\title{
Separating the wheat from the chaff
}

\author{
Claus Runge
}

Published online: 23 February 2012

(C) Springer-Verlag 2012

\section{The new pricing and reimbursement system in Germany}

Germany witnessed a major paradigm shift in its pricing and reimbursement system on 1 January 2011: while immediate patient access to new pharmaceuticals continues to be guaranteed, free pricing of innovative, non-referencepriced pharmaceuticals will be limited to 12 months.

In accordance with the new legislation known as the 'pharmaceutical market restructuring act' (AMNOG), new pharmaceutical products being placed on the market are subject to a 3-month-long rapid benefit assessment process $[1,2]$. During this period, the German rationing body, the Federal Joint Committee (GBA), determines the additional clinical benefit vis-a-vis "appropriate comparator therapies" on a scale ranging from ' 1 ' for major therapeutic advances to ' 6 ' for inferiority to the 'appropriate comparator therapy' (see Table 1).

Usually (but not necessarily) the German Institute for Quality and Efficiancy in the Healthcare system (IQWiG) runs product assessments on behalf of the GBA, based on a manufacturer's reimbursement dossier (see Fig. 1).

If a product proves to have additional clinical benefits from a GBA perspective it will qualify for downstream pricing negotiations with the Umbrella Organization of Statutory Health Insurers (GKV-SV). If there is no evidence of additional clinical benefit, reimbursement will be limited to existing reference price (RP) levels in the therapeutic class or-when no RP is applicable-will be capped at the price level of the appropriate comparator therapy. The rapid assessment procedure can also apply

C. Runge ( $\square)$

Hamburg, Germany

e-mail: Claus.Runge@astrazeneca.com optionally to in-market pharmaceuticals at the sole discretion of the GBA. The price-setting process itself consists of three phases: an assessment period (6 months), the negotiation (6 months) and a potential arbitration process ( 3 months). In case of arbitration, reimbursed prices will become valid retroactively as of 13 months post-launch. ${ }^{1}$

\section{The policymaker intention}

According to the Ministry of Health, AMNOG is a pure cost containment exercise that is aimed at closing the absence of price control in the non-reference-priced pharmaceutical market [4]. Continued expenditure growth in this segment has been in the public eye for quite a while. In particular, German price levels as compared to European prices have been the focus of heated debates.

The policymaker intention with AMNOG is to 'separate the wheat from the chaff' in a first assessment step, filtering out 'true innovations' from what assessment bodies consider to be 'analogues with little or no incremental value'. In a second step, the aim is to approximate the German to the European Union (EU) price levels, and to reach a reconcilement of interests via central negotiations between the monopolist (as a manufacturer might offer a unique, hardly interchangeable product) and the monopsist (as the GKV-SV negotiates for both statutory and private insurers making up nearly $100 \%$ of the purchasing power).

\footnotetext{
${ }^{1}$ For products launched between January and July 2011, a transition period applied prolonging the assessment process prior to negotiation by 6 months. However, for these products prices will also be valid retroactively from launch date plus 12 months onwards.
} 
Table 1 Benefit assessment ratings according to the decree issued by the Ministry of Health [3] $\frac{\text { Benefit assessment ratings }}{1 \text { Major additional benefit }}$

2 Important additional benefit

3 Slight additional benefit

4 Additional benefit exists but is not quantifiable

5 No additional benefit has been proven

6 The benefit of the pharmaceutical to be assessed is smaller than the benefit of the appropriate comparative therapy
Lasting major improvement of the therapy-relevant benefit

Previously not attained compared to the appropriate

comparative therapy

Recovery from the disease

A significant extension in the duration of survival

Long-term freedom from severe symptoms or

Extensive avoidance of serious side effects

Significant improvement of the therapy-relevant benefit

Previously not attained compared to the appropriate

comparative

Reduction of serious symptoms

A moderate extension of the duration of life

An alleviation of the disease that is noticeable for the patients,

A relevant avoidance of serious side effects, or

A significant avoidance of other side effects

Moderate/not just minor improvement of the therapy-relevant benefit

Previously unattained compared to the appropriate comparative therapy

Reduction of non-serious symptoms

Relevant avoidance of side effects

Scientific data basis does not allow such a quantification
In order to bridge the time until AMNOG reaches its projected cost-saving potential, the ruling coalition decided to back the insurers by passing the statutory health insurance finance bill (GKVFinG), which introduced a $16 \%$ mandatory manufacturer rebate until 2013, buttressed with a price moratorium on patent-protected pharmaceutical products that are not regulated by RP schemes [5].

\section{A bumpy start into the first assessments}

The paradigm shift associated with the new approach presents all parties involved with serious challenges. Protagonists on both sides are dragging far too many relics along with them for the planned sprint through the 3-month period. Thus, even at this early stage, the just-started AMNOG prototypes reveal four areas of heavy controversy between industry and decision-making bodies such as the GBA.
GBA consultation

With regard to their initial interactions, several manufacturers report that consulting the GBA more closely resembles adjudication with associated costs than an actual consulting session. The dilemma of the GBA Office is obvious: it can, as a rule, provide procedural answers, but it cannot provide factual answers based on content to inquiries from impacted manufacturers, since decision-making in the GBA subcommittee for pharmaceutical products is already concluded. Scientific dialogue is reported to be hampered in this set-up. The GBA has already acknowledged that the format can be further developed in this respect [6].

The GBA also offers the opportunity to consult prior to the start of licensing studies. A preliminary vote cannot be taken as no manufacturer is known to have gone through this already. Great significance is accorded to this type of 


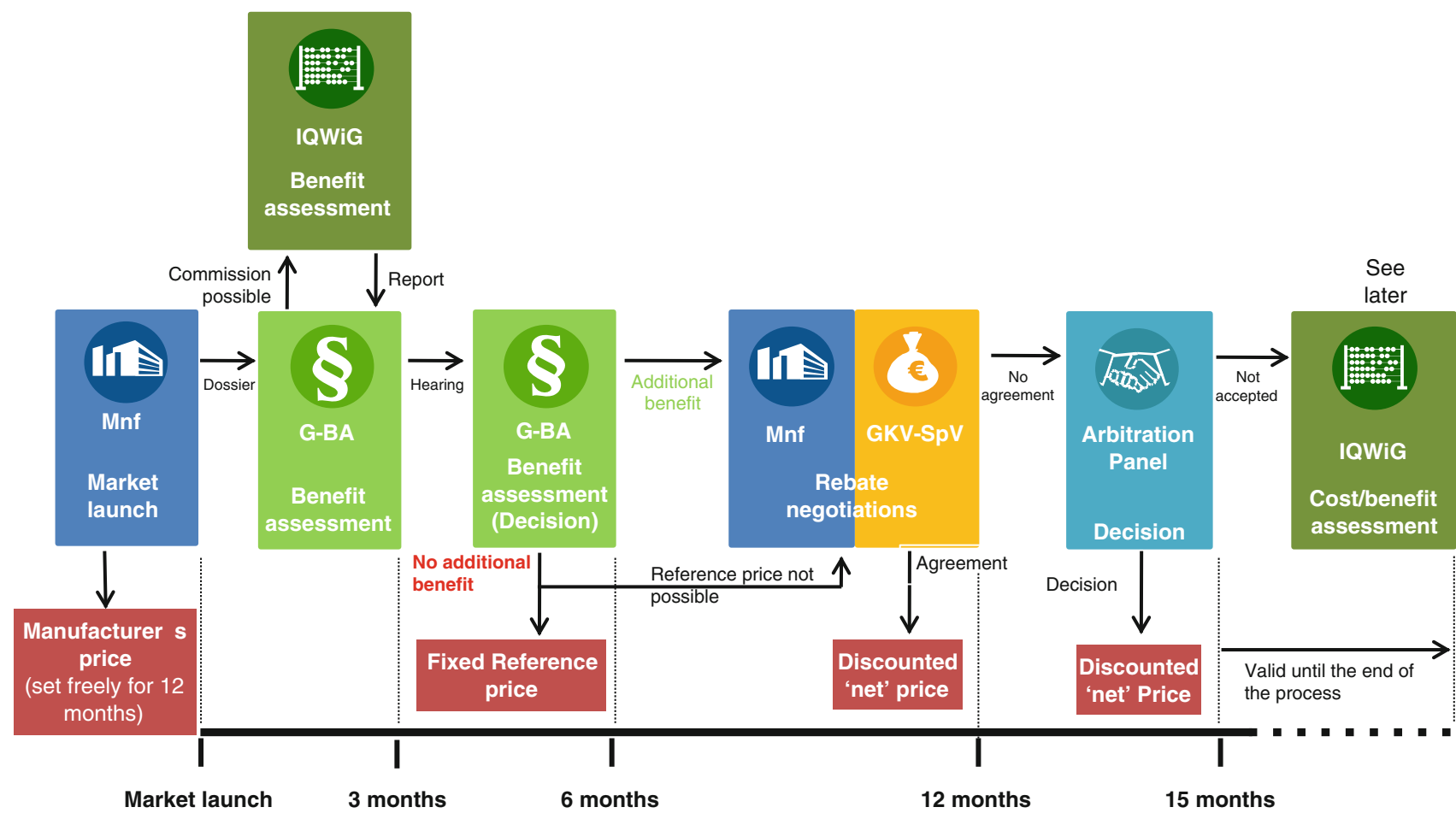

Fig. 1 Schematic overview of benefit assessment and price setting according to the 'pharmaceutical market restructuring act' (AMNOG) law

consultation, which is already well established with the National Institute for Clinical Excellence (NICE) in the UK. Meetings can be undertaken with the optional participation of the Federal Institute for Pharmaceutical Products and Medical Devices (BfArm) and the Paul-Ehrlich-Institute (PEI) - the two German regulatory bodies. Even if this interaction provides an opportunity for manufacturers to adapt the significant investment in phase III to meet future requirements of the early assessment more effectively, the advice given is not binding. Moreover, it still remains to be seen whether the allegedly very high requirements in terms of evidence provision can be met by the manufacturers (1) in the context of confirmatory trials, and (2) at the effective date of pharmaceutical product licensing. Finally, it is unclear yet whether local GBA concerns will fit into the broader context of international study programs.

\section{Choice of comparators}

According to industry representatives, the selection of appropriate comparator treatments by the GBA is suspected to be the most strategy-prone component of the early assessment process [7]. It has a direct influence on the end result: the informative value of the phase III study of a newly licensed pharmaceutical product, for instance, might become weakened systematically by choosing comparative treatments that not only deviate from the licensing studies, but also by choosing multiple comparator treatments for (consequently smaller) patient groups. Thus the manufacturer is forced to move away from the consensus with regulatory agencies such as EMA with regard to the comparator(s) and to carry out indirect comparisons versus non-trial comparators. Indirect comparisons bear the risk of less reliable results being reflected in the product assessment. Since case number planning in studies is adjusted for specific patient groups, post hoc sub-group analyses as demanded by the GBA may lead to a further watering down of the observed study effects.

Since GKV-SV representatives in the GBA selecting the appropriate comparative treatment are the same as those who then negotiate the price, there is a potential conflict of interest. If pricing policy is already running in the way of comparator selection to the detriment of industry, the underlying AMNOG concept - namely that of a fair balance of interests when rewarding innovations-will appear at least endangered according to market observers. Unlike national authorities in other EU countries that might be willing to safeguard basic industry interests, the GKV-SV's sole interest is stability of insurance premiums, rather than fostering of innovation [8].

GBA protagonists, however, refer to their self-defined rules and state that any comparator chosen to date has fulfilled the following set of criteria [9]:

1. In cases where the application of a pharmaceutical is eligible as a comparative therapy, as a rule the pharmaceutical must be approved for the therapeutic indication. 
2. In cases where a non-pharmaceutical treatment is eligible as a comparative therapy, this treatment must be suitable to be applied within the framework of the statutory health insurance.

3. As comparative therapies, those applications of pharmaceuticals or non-pharmaceutical treatments should be chosen whose patient-relevant benefit has already been confirmed by the Federal Joint Committee.

4. The comparative therapy shall be part of the appropriate therapy in the therapeutic area according to the generally acknowledged state of medical knowledge.

5. In case of several alternative therapies, the more economic should be chosen, preferably a therapy for which a RP has been set.

It is known that the GBA has already revised the comparative therapy in at least one ongoing assessment after the manufacturer had asked the Regulatory Agency BfArm to intervene.

\section{Classification grid}

To the surprise of the broader public the IQWiG has suggested a classification grid translating clinical trial results into innovation ratings through the backdoor of the first AMNOG process-although the GBA is the institution legally authorized to define methods that reflect binding judgement calls for statutory health insurance.

Based on the IQWiG suggestions, only the spot and width of the confidence intervals derived from randomised clinical trials, but not the effect size itself, lead to classifications 1-3 [10]. Furthermore, there is no hint as to the way different endpoints collected in a clinical trial should be weighted one versus the other, or how to handle classification issues across different indications. Patient preferences are not accounted for either. The classification remains an exercise of relative efficacy without acknowledging the absolute gain in health units.

Spontaneously, the GBA itself has rejected the IQWiG grid from becoming the backbone of future assessments and seeks to open up a broader stakeholder discussion prior to making legally binding decisions in this regard. Therefore, first assessments will be based solely on the general classification criteria described in the Federal Ministry of Health's decree that details out the AMNOG bill.

\section{Price negotiation}

In autumn, Industry and the GKV SV finalised a master agreement defining a rather imprecise set of criteria on how to negotiate reimbursed prices in future [11]. The innovation rating itself will play a role, as well as prices of comparators and other treatment options in the same therapeutic field. Volume agreements will also be part of the equation. As no agreement could be reached between industry and the GKV SV as to the legally foreseen impact of EU prices, a solution needs to be found by the newly established arbitration board in this regard: while Industry is calling for equipotent $\mathrm{EU}$ countries to be thrown into a reference pricing country basket (as already established in the area of vaccines), the GKV SV calls for countries such as Romania to become relevant pricing benchmarks for Germany.

Finally, it will be interesting to see how AMNOG-proven innovations will achieve price premiums over generic comparators in the absence of value based pricing elements.

\section{Résumé of the 1st year under the new scheme}

In 2011, the GBA had a total of 24 pharmaceuticals to deal with under the new legislation [12]. At least two manufacturers decided not to hand in dossiers for their products at all, making them subject to RP immediately.

Two other cases attracted significant media attention: based on the choice of comparative therapies by GBA, Novartis pulled a blood-pressure lowering combination drug (Rasilamlo ${ }^{\circledR}$ ) off the market, and Boehringer Ingelheim decided not to supply wholesalers with a new oral antidiabetic drug (Trajenta ${ }^{\circledR}$ ) until the final price for the product was determined. According to the companies' press releases, both anticipate an unsatisfactory outcome due to 'unfair' choice of comparative therapies-which has been rejected strongly by the GBA [13].

The only full assessment to become available in 2011 was AstraZeneca's anti-clotting agent Ticagrelor (Brilique), which was approved for treating patients with acute coronary syndrome (ACS) [14]. AstraZeneca decided to enter the AMNOG process voluntarily although the company could have launched the product under the old pricing framework in December 2010.

In combination with aspirin, Ticagrelor has proven superiority versus the current standard of care in ACSclopidogrel plus aspirin. According to the licensing trial, treating 1,000 patients with Ticagrelor instead of clopidogrel prevents 11 cardiovascular deaths and 11 myocardial infarctions in the post-event year [15]. Several HTA agencies in Europe, including NICE, the Scottish Medicines Consortium and the Danish Agency have already backed Ticagrelor's broad use in ACS at significant premiums over generic clopidogrel [16].

In contrast to the other agencies' practice, and in contrast to the manufacturer's position, the GBA has defined comparative therapies other than clopidogrel in two subsets of patients (share of total patients): prasugrel plus aspirin in patients with ST-elevation myocardial infarctions undergoing primary coronary interventions, STEMI PCI (23\%), 
and aspirin monotherapy in patients with ST-elevation myocardial infarctions undergoing coronary artery bypass grafting, STEMI CABG (2\%); Clopidogrel plus aspirin is the comparative therapy for STEMI patients undergoing thrombolysis, STEMI MM (3\%) as well as for the combined group of Non-STEMI patients, NSTEMI \& Unstable Angina patients, UA (72\% combined) [17].

This first case already reveals the decisive impact of comparative therapies for benefit assessment. If the GBAin line with the European Medicine Agency-had chosen the current therapeutic standard Clopidogrel plus aspirin as the comparator for the entire group of ACS patients, the IQWiG would have come up with a rating of ' 1 ' (the highest) for Ticagrelor according to its suggested grid. Instead, it could only give a rating of ' 2 ' for NSTEMI/UA (equivalent to $\sim 3 / 4$ of all patients) due to loss of statistical power in the post hoc sub-group analysis. For the three STEMI subgroups, IQWiG came up with 'no additional benefit proven'. This is not surprising since no comparative data are available for Ticagrelor plus aspirin versus aspirin montherapy (in STEMI CABG) or versus prasugrel (in STEMI PCI). The STEMI MM subgroup is difficult to single out in clinical practice, and AstraZeneca's licensing trial was not powered to show a difference in this small sub-entity either. It is important to understand that, in all three STEMI subgroups, Clopidogrel plus aspirin is used as a standard in $\sim 80 \%$ of all patients in clinical practice and recommended in both international and national guidelines. So, despite it being the current standard of care, the GBA did not choose Clopidogrel plus aspirin as a comparator therapy. The reason for this choice is that GBA considers Clopidogrel not to be in alignment with the GBA self-defined criteria for comparative therapies.

The indirect comparison that AstraZeneca had undertaken versus prasugrel was rejected by IQWiG on different grounds: in order to meet IQWiG's patient matching requirements for the indirect comparison, AstraZeneca would have needed access to the unpublished raw data of Lilly's prasugrel licensing trial. For obvious reasons, this was out of the question. It will be interesting to see if the policymaker's wish to give manufacturers the opportunity to perform indirect comparisons will be undermined by setting such non-attainable standards.

In its final Ticagrelor assessment, however, GBA partially overruled IQWiG's recommendation and decided to split the STEMI PCI subgroup further. The assessment outcome is [14]:

- "Important additional benefit" (rating of 2) for Non ST-Elevation Myocardial Infarction/Unstable Angina (NSTEMI/UA); comparator: Clopidogrel + aspirin

- "Additional benefit but not quantifiable" (rating of 4) for STEMI/PCI patients over 75 years or those patients with prior stroke or TIA; comparator: prasugrel + aspirin
- "No additional benefit proven" which formally translates into a 'as good as' (rating of 5) for the three following STEMI patient sub-populations:

- STEMI/PCI (separate from the above); comparator: prasugrel + aspirin

- STEMI/CABG (ST-elevation myocardial infarction coronary artery bypass graft); comparator: aspirin monotherapy

- STEMI medically managed; comparator: Clopidogrel + aspirin

In other words, the GBA acknowledges an incremental benefit for Ticagrelor versus Clopidogrel in NSTEMI/UA and versus prasugrel in a subset of STEMI PCI patients which in sum make up $\sim 80 \%$ of the overall ACS population.

In the light of only two further (preliminary) assessments (pirfenidon and boceprevir) that are currently available this is a remarkably positive outcome for Ticagrelor - the orphan drug Pirfenidon was entirely rated with ' 5 ' while Boceprevir achieved two ratings of ' 4 ' and two ratings of ' 5 ' for various subpopulations).

Budget impact analysis

In the dossier, the manufacturer also needs to provide a budget impact analysis from a payer's perspective. In the Ticagrelor case, the GBA ignored the manufacturer's provision of cost saving data ( $257 €$ per patient per year) based purely on formal grounds. From a GBA perspective, only the additional costs mentioned in the SmPc can be accounted for (so $0.80 €$ for a quarterly recommended diagnostic test were added). The GBA stated in the November hearing that any cost offset that lower the incremental costs of Ticagrelor should be discussed in the negotiation with the GKV-SV, or could be become relevant in a cost-benefit analysis that any party can ask for post arbitration.

\section{Outlook}

Benefit assessment

Benefit assessment is all about GBA's 'sense of proportion'. The new AMNOG tool provides unprecedented power to the GBA, which is the key decision-making body of the vastly autonomous German self-administration. It represents payers and providers, while patient organizations are non-voting members. Industry is not sitting at the table and has limited rights to appeal to any of the body's decision. Lawsuits can be filed only at the very end of the AMNOG process and usually take several years before being decided at Social Courts-in the meantime, any 
decision taken by the GBA remains valid. Therefore industry has voiced some concerns that the GBA's primary goal of cost containment will interfere with the fairness of its appraisals. It is yet unclear whether the fair balance of interests as desired by the policymakers will be translated into practice. The first cases will tell.

Basically, AMNOG offers the opportunity to revisit the initial assessment whenever the manufacturer provides more compelling evidence and is ready to re-run the assessment process. From the author's perspective, industry needs to adapt its study programmes to the AMNOG challenges if it wants to continue to be successful in Germany. A Charles Darwin citation applies very well to this fundamental challenge: "It is not the strongest of the species that will survive nor the most intelligent one. It is the one most adaptable to change."

\section{Negotiations}

Next year's first price negotiations will become a key area of focus. As of January 2012, Ticagrelor will become the spearhead of the newly established central pricing negotiations between manufacturer and GKV-SV. Negotiating parties will have to place a bet on the product price if they leave the table with no agreement: the arbitration board's code of practice is still unknown.

\section{References}

1. Bundesministerium für Gesundheit-Kommunikationsstab (Öffentlichkeitsarbeit): http://www.bundesgesundheitsministerium.de. BMG-G-10050 (2010)

2. Der Bundepräsident: Gesetz zur Neuordnung des Arzneimittelmarktes in der gesetzlichen Krankenversicherung (Arzneimittelmarktneuordnungsgesetz-AMNOG). Bundesgesetzblatt Nr. 67, 2262-2277 (2010)

3. Der Bundespräsident: Verordnung über die Nutzenbewertung von Arzneimitteln nach § 35a Absatz 1 SGB V für Erstattungsvereinbarungen nach $\S 130 \mathrm{~b}$ SGB V (Arzneimittel-Nutzenbewertungsverordnung-AM-NutzenV). Bundesgesetzblatt Nr. 68, 2326-2327 (2010)

4. Regierung online: Neuordnung am Arzneimittelmarkt-Einsparungen von bis zu zwei Milliarden Euro. http://www.bundesregi erung.de Nr. 089 07/2010 (2010)
5. Der Bundespräsident: Gesetz zur nachhaltigen und sozial ausgewogenen Finanzierung der Gesetzlichen Krankenversicherung (GKV-Finanzierungsgesetz-GKV-FinG). Bundesgesetzblatt Nr. 68, 2309-2320 (2010)

6. Rainer Hess, Chairman of the GBA: Public discussion at the 'III. Expert forum AMNOG' in Berlin on the 7th of June (2010)

7. Verband forschender Arzneimittelhersteller: Stellungnahme zum Gesetzentwurf der Bundesregierung Entwurf eines Gesetzes zur Verbesserung der Versorgungsstrukturen in der gesetzlichen Krankenversicherung (GKV-VSG). http://www.vfa.de/de/wirtsc haft-politik/stellungnahmen/stnm-gkv-vstg (2010)

8. Kaesbach, W.: Frühe Arzneimittel-Nutzenbewertung im Rahmen des AMNOG. Auswirkung auf die GKV. 8. Diskussionsforum der SEG 6 und des Bereichs ebM des MDS, Dortmund (2010)

9. Gemeinsamer Bundesausschuss: Chap. 5: Assessment of the benefits of pharmaceuticals according to $\S 35$ a SGB V. Downloaded from http://www.english.g-ba.de/special-topics/pharmace uticals/benefitassessment/ (2010)

10. IQWiG: Ticagrelor-Nutzenbewertung gemäß $\S 35 \mathrm{a}$ SGB V. Downloaded from https://www.iqwig.de/download/A11-02_Tica grelor_Nutzenbewertung_\%C2\%A735a_SGB_V_.pdf: attachment A, pp. 86-92 (2010)

11. GKV-Spitzenverband, Bundesverband der Arzneimittelhersteller (BAH), Bundesverband der Pharmazeutischen Industrie (BPI), progenerika, Verband der forschenden Pharma-Unternehmen (vfa): Gemeinsame Pressemitteilung Einigung in fast allen Punkten erzielt. Downloaded from https://www.gkv-spitzenver band.de/GemPM_20111013_Arzneimittel.gkvnet (2010)

12. Gemeinsamer Bundesausschuss: Downloaded from http://www. g-ba.de/informationen/nutzenbewertung/ on 28 December (2011)

13. Gemeinsamer Bundesausschuss: Press release: downloaded from http://www.g-ba.de/institution/presse/pressemitteilungen/403/ (2010)

14. Gemeinsamer Bundesausschuss: Beschluss des Gemeinsamen Bundesausschusses über eine Änderung der Arzneimittel-Richtlinie (AM-RL): Anlage XII-Beschlüsse über die Nutzenbewertung von Arzneimitteln mit neuen Wirkstoffen nach $\S 35 \mathrm{a}$ SGB V-Ticagrelor vom 15. Dezember 2011. Downloaded from http://www.g-ba.de/downloads/39-261-1418/2011-12-15_AM-RLXII_Ticagrelor.pdf (2010)

15. Wallentin, L., et al.: Ticagrelor versus clopidogrel in patients with acute coronary syndromes. N. Engl. J. Med. 361(11), 10451057 (2009)

16. Baertschi, G., Runge, C.: In Rebscher/Kaufmann (eds.) Qualitätsmanagement in Gesundheitssystemen: Erfahrungen mit der frühen Nutzenbewertung aus Sicht der Industrie, pp. 501-511(2010)

17. AstraZeneca: Dossier zur Nutzenbewertung gemäß § 35a SGB V Ticagrelor $\left(\right.$ Brilique $^{\circledR}$ ). Downloaded from http://www.g-ba.de/ informationen/nutzenbewertung/18/ (2010) 